\title{
INVISIBILIDADE DA POPULAÇÃO RIBEIRINHA AO ACESSO E EFETIVAÇÃO DAS POLÍTICAS PÚBLICAS: AS EXPERIÊNCIAS NO TERRITÓRIO EM DISPUTA DE ANAJÁS-PA
}

\begin{abstract}
INVISIBILITY OH THE RIVERSIDE POPULATION TO THE ACESS AND EFFECTIVENESS OF PUBLIC POLICIES: EXPERIENCES IN THE DISPUTED TERRITORY OF ANAJÁS-PA
\end{abstract}

Eunápio Dutra do Carmo ${ }^{1}$
http://lattes.cnpq.br/7347286742599751
$\underline{\text { https://orcid.org/0000-0002-8186-8789 }}$

Maria Elisane de Souza Silva²

http://lattes.cnpq.br/4624395709104169 https://orcid.org/0000-0002-1455-5635

Recebido em: 8 de junho de 2020

Aprovado em: 19 de agosto de 2020

RESUMO: A intensificação da ocupação de terras por agentes capitalistas no território de Anajás, no estado do Pará, impulsiona a invisibilidade da população ribeirinha frente às políticas públicas. Por isso, a necessidade de compreender as experiências desse território como forma de desvelar a realidade em que essa população está inserida. O histórico quadro político revela como as formas de disputa, dominação e resistência são agenciadas na correlação de força presente no município. É deste processo social que o território emerge como categoria central de análise crítica, tanto na perspectiva de entender a lógica de expropriação da terra, mas, sobretudo, a agudização das expressões da questão social que os ribeirinhos vêm enfrentando. Com base em documentos históricos, entrevistas com entidades sociais e pesquisa de campo, via Centro de Referência da Assistência Social-CRAS, junto a membros de comunidades ribeirinhas, observa-se a manutenção de estruturas políticas e econômicas que privilegiam a elite regional/local em detrimento das populações camponesas, ribeirinhas e de pequenos proprietários que são socialmente invisibilizados, não obstante a permanente luta e resistência que reatualizase nos modos de vida, na preservação da natureza e na garantia de direitos. Todas foram herdadas e forjadas na história secular de índios, quilombolas e caboclos que enfrentaram processos genocidas de colonização e que estão inscritos, até hoje, no território.

\footnotetext{
${ }^{1}$ Docente da Faculdade de Serviço Social (UFPA - Campus Universitário do Marajó-Breves). Pós-Doutor em Desenvolvimento Socioambiental (2015), Doutor em Ciências Humanas: Educação pela PUC-Rio (2010). Coordenador do Programa Redes de Comunidades Ribeirinhas, membro do Grupo de Pesquisa Estado, Território, Trabalho e Mercados Globalizados e integrante da Rede de Pesquisa sobre Pedagogias Decoloniais na Amazônia. E-mail: eunapiodocarmo@ gmail.com.

2 Discente do $6^{\circ}$ período da Faculdade de Serviço Social (UFPA - Campus Universitário do Marajó-Breves) e integrante do Programa Redes de Comunidades Ribeirinhas. E-mail: mariaelisane1994@gmail.com.
} 
Palavras-chaves: Território. Exploração. Ribeirinhos. Políticas públicas.

\begin{abstract}
The intensification of land occupation by capitalist agents in the Anajás territory had boosted the invisibility of the riverside population in relation to public policies. Therefore, the need to understand the experiences of that territory as a way to unveil the reality in which this population is inserted. The historical political picture reveals how the forms of dispute, domination and resistance are managed in the correlation of strength present in the municipality. It is from this social process that the territory emerges as a central category of critical analysis, both in the perspective of understanding the logic of expropriation of the land, but, above all, the sharpening of the expressions of the social issue that the riverside people have been facing. Based on field research, via CRAS, with the riverside communities, historical documents, interviews with social entities, it is observed the maintenance of political and economic structures that privilege the regional / local elite to the detriment of the peasant, riverside and small populations owners who are socially invisible, notwithstanding the history of struggle and resistance that is updated in ways of life, in the preservation of nature and in the guarantee of rights. All were inherited and forged in the secular history of Indians, quilombolas and caboclos who faced genocidal colonization processes and who are still registered in the territory today.
\end{abstract}

Keywords: Territory. Exploration. Ribeirinhos. Public policy.

\title{
INTRODUÇÃO
}

Ao longo dos anos, os processos de expropriação capitalista no território de Anajás resultaram em violações de direitos em vários contextos sociais, sendo as populações tradicionais as mais afetadas. Para compreensão da realidade do município de Anajás, estado do Pará, é necessário fazer um movimento crítico-reflexivo dos acontecimentos que se sucederam como estratégias capitalistas para expropriação das terras, impactos ambientais, carência de informações sobre o uso e direito das terras e as principais formas de enfrentamento. Todas imbricadas na territorialidade construída a partir desses episódios, além de compreender a importância da responsabilidade em efetivar as políticas públicas e a rede de serviços sociais no território e garantir os direitos sociais.

Por essas trilhas da história social marajoara, o trabalho ocupa-se em analisar o agenciamento do território de Anajás aos interesses da agenda capitalista da elite econômica como resultado da invisibilidade da população ribeirinha frente às políticas públicas. A pesquisa de campo em Anajás priorizou como estratégias: acompanhar ações das entidades, conversar com membros de comunidades ribeirinhas e acessar documentos históricos para compreender como a não efetivação das políticas públicas fragiliza o território e o exercício da cidadania, decorrente do processo histórico ligado à exploração capitalista ainda pouco discutido e pouco documentado ${ }^{3}$ no município.

A coleta de dados ocorreu no período de outubro a dezembro de 2019, inicialmente, no âmbito do Centro de Referência da Assistência Social - CRAS Yulis Jordán durante o estágio

\footnotetext{
${ }^{3}$ No processo de coleta de dados bibliográficos, foram observados poucos trabalhos de pesquisa sobre o munícipio, principalmente no que diz respeito os problemas sociais que afetam ou afetaram o território tendo em vista o processo sócio-histórico.
}

PRACS: Revista Eletrônica de Humanidades do Curso de Ciências Sociais da UNIFAP 
I, da discente, autora desse artigo. Durante as atividades de estágio, foram observadas demandas com foco na geração de informação e formação coletiva e autônoma dos usuários para uma cultura e garantia de direitos na perspectiva da emancipação social numa realidade marcada pela ampliação do poder econômico e político das oligarquias locais e aprofundamento da desigualdade social. Somado a isso, o campo de estagio revela um cotidiano desafiador por ser entendido como um espaço de contradição decorrente da relação capital - trabalho, mas também de direcionamento social e político, indispensável para a elaboração de estratégias e intervenções capazes de atender a realidade dos sujeitos da política.

É importante compreender que o estágio supervisionado deve ser conduzido com base nos seguintes aparatos legislativos: Lei de regulamentação da profissão (Lei nº662/1996), Diretrizes Curriculares do Estágio Supervisionado do Curso de Serviço Social - ABEPSS, Código de Ética do Assistente Social - Lei 8.062/93 e da Política em que a instituição está inserida, como a Política Nacional de Assistência Social - PNAS, aprovada pela Resolução n ${ }^{\circ} 145$, de 15 de outubro de 2004, do CNAS, no qual o CRAS está inserido. O conjunto dessas leis viabilizam uma formação crítica e, fundamentalmente, ética na perspectiva sócio-histórica a partir das demandas da classe trabalhadora.

A direção ético-política aponta para a importância da produção de conhecimento envolvendo valores que partem do principio de que não se pode desconsiderar o passado, ou impor modos de vida aos sujeitos da política, mas sim ter um olhar sensível à realidade de cada pessoa, além de apresentar possiblidades de participação, reflexão e ação. Também envolve aspectos institucionais como instrumento de direcionamento para o agir profissional como projeto ético-politico do Serviço Social, no qual centra-se o compromisso tendo em vista a democracia com a classe trabalhadora.

Também fez parte da coleta de dados, importantes incursões junto às comunidades ribeirinhas, bem como, nos espaços de interação dos ribeirinhos (casas, filas e ruas) e de ribeirinhos vindos de outros municípios, como Breves e Afuá, onde foram discutidos modos de vida, problemas sociais e formas de resistência para problematizar temas taticamente camuflados pelas ideologias dominantes e naturalizados por uma ordem social hegemônica e racista. Importa destacar novamente a dimensão no respeito, valorização e escuta com os grupos socialmente diferenciados, na medida em que os mesmos são sujeitos da política, portanto, ativos e com potência social e não meros repassadores de informação.

No mês de março e abril de 2020, foram realizadas conversas com entidades sociais (Igreja Católica, associações de ribeirinhos e colônia de pescadores) foram abordadas as causas das disputas territoriais e formas de organização social. O Programa Redes de Comunidades Ribeirinhas da Faculdade de Serviço Social (FACSS) do Campus Marajó-Breves da Universidade Federal do Pará, através do co-autor desde artigo, contribui com mediações sobre informações, apuração de dados e debates a respeito da territorialização das vidas ribeirinhas e lutas por direitos socioterritoriais.

Ainda nessa direção, somado a isso, a pesquisa documental em relatórios, boletins e jornais ajudaram na compreensão das correlações de forças e a necessária produção da contra-informação. A abordagem histórico-crítica inspira a forma de análise contra-hegemônica dos dados e, ao mesmo tempo, privilegia o entendimento de que a conflitualidade é inerente ao território, portanto, está na raiz da questão agrária na Amazônia, ou seja, são conflitos pela imposição de um modelo de desenvolvimento genocida, racista e de injustiça ambiental em detrimento aos modos de ser, fazer e memoriar dos grupos socialmente forjados nas territorialidades milena- 
res, cuja história é elemento de resistência.

Com o intuito de promover reflexões sobre o município, essa discussão envolve pontos cruciais que ajudam entender as relações sociais, conflitos, identidades, territorialidade e o aligeiramento das estratégias neoliberais presente no território. Para tanto, o trabalho foi estruturado de forma a contextualizar as condições históricas da formação socioeconômica do município, sinalizando a ocupação territorial, as primeiras formas de exploração capitalista na região, os ciclos de exploração que ocorreram e que vem ocorrendo, bem como as consequências dessas ações.

Em seguida, é feita a abordagem sobre relações de poder e conflitos socioambientais em decorrência da dinâmica que ocorre no território. Dando prosseguimento, pontua-se sobre o contexto social e político de como está à atuação dos poderes públicos em efetivar políticas que atenda às necessidades presentes dos sujeitos da política. E, posteriormente, as resistências como possibilidades e dificuldades frente a um cenário neoliberal, que põem em risco até mesmo a preservação do modo de vida das populações ribeirinhas.

\section{FORMAÇÃO SOCIOECONÔMICA DO MUNICÍPIO DE ANAJÁS}

Os primeiros povos que ocuparam o território de Anajás foram os índios Inajás, pertencentes à tribo dos Nheengaíbas. Desse modo, os Inajás foram um dos principais povos indígenas a resistir e lutar bravamente contra a colonização no Marajó ${ }^{4}$. Vale ressaltar que o primeiro grupo de colonizadores a chegar à região foram os Jesuítas, sob o comando de Padre Antônio Viera, enviados para catequisar os índios (PREFEITURA DE ANAJÁS, 2017). Esse grupo estava sediado no território próximo ao território de Anajás, atual cidade de Breves, com o intuito de conquistar as regiões ao entorno, incluindo Anajás (idem). Abaixo, imagens do mapa do arquipélago do Marajó e da cidade de Anajás, que se encontra ao centro do arquipélago.

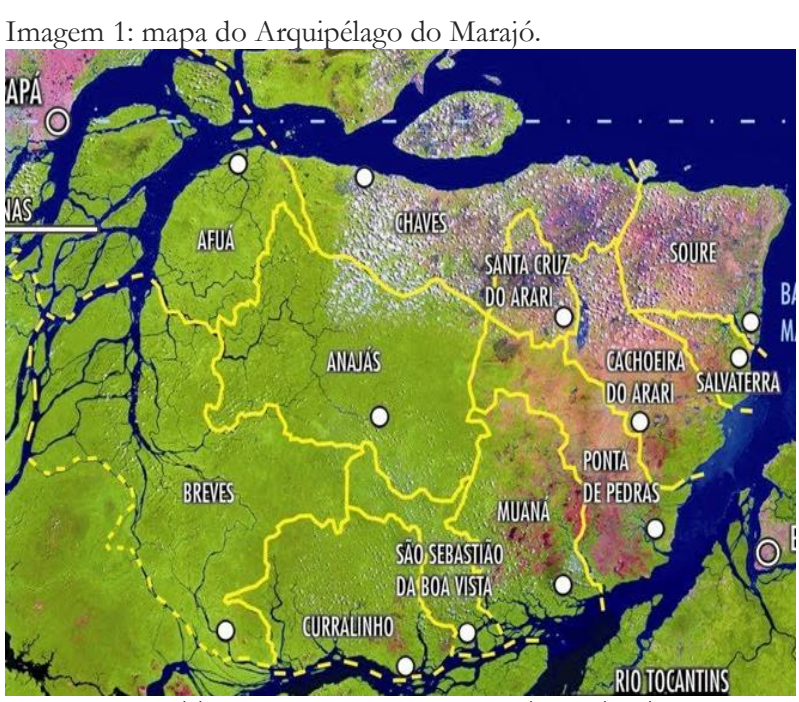

Fonte: http://marajoando.blogspot.com/2009/12/o-mapa-dailha.html. acesso em 15 de abril de 2020.

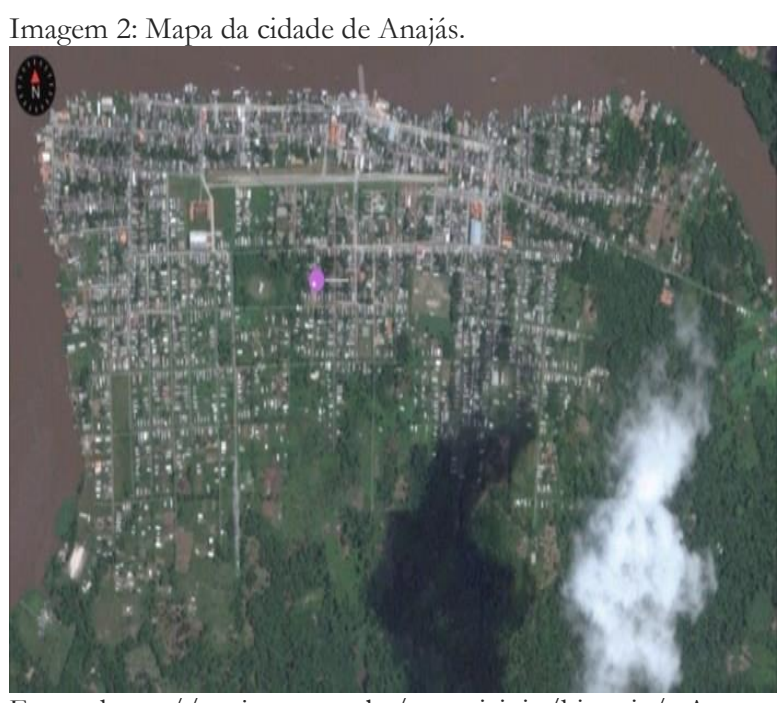

Fonte: https://anajas.pa.gov.br/omunicipio/historia/. Acesso em 23 de maio de 2020.

\footnotetext{
${ }^{4}$ Em linhas gerais, a colonização no Marajó se deu com a chegada dos jesuítas para explorar o espaço a partir do desenvolvimento econômico. Isso implicou em confronto com os povos nativos, consequentemente em extermínio de muitos desses, até mesmo da cultura. (PREFEITURA DE ANAJÁS, 2017).
} 
No período pré-colonial Anajás foi chamada de Mocoões. De acordo com informações disponibilizadas pelo IBGE (2017), o território do município passou por disputas entre os municípios vizinhos, tais como fuá, Chaves e Breves. Em 1870, foi denominado Menino de Deus do Rio Anajás e oito anos depois o nome foi extinto e o território passou a pertencer ao município de Breves, no estado do Pará. No ano de 1882, a região voltou a ser denominada Menino de Deus do Rio Anajás e emancipada de Breves, foi então criada a cidade. Em 1930 seu território passou a pertencer a Afuá e em 1938 foi novamente emancipado e fragmentado em três zonas: Anajás, Furo do Breu e Trovão. Só em 1960 as zonas foram unidas.

Conforme o Plano de Desenvolvimento Territorial Sustentável do Arquipélago do Marajó (GRUPO EXECUTIVO INTERMINISTERIAL, 2007) não existe documentos históricos escritos que apresentem informações a respeito do modo de vida das populações marajoaras no período pré-colonial. Há uma lacuna nos conhecimentos acerca dos primeiros povos originários da região e a consequência disso é o não reconhecimento da raiz indígena como parte da identidade cultural dos munícipes. Pouco é fomentado sobre a história da região, fato que pode estar ligado às tímidas manifestações culturais que são pouco valorizadas pelos munícipes, por exemplo, a maior festa é a do padroeiro da cidade 5 , não há nenhuma comemoração ou celebração ligada aos povos originários.

Todavia, esse aparente "desconhecimento" tem relação com epistemicídios (SANTOS, 2012) provocados pela história oficial que nega todo e qualquer informação dos fatos históricos dos modos de vida, relações sociais, produção econômica e atividades culturais vinculadas àqueles atores sociais marginalizados e frontalmente explorados. O desenvolvimento do município foi desencadeado pela exploração dos recursos naturais de forma desenfreada, por isso esse "desenvolvimento" ganha historicamente aspecto de precarização, observado principalmente pela pouca eficiência em efetivar políticas básicas à população. Nas imagens abaixo, registros da cidade em fotos antigas e no momento atual.

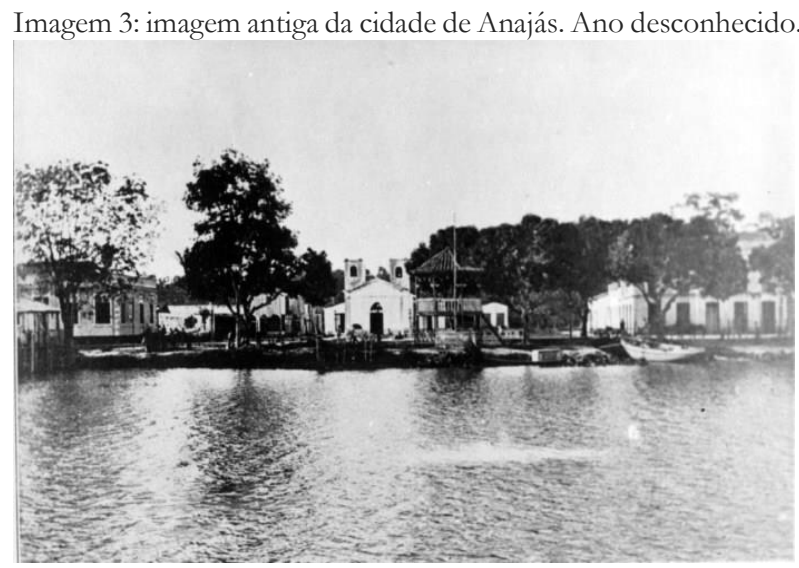

Fonte: https://anajas.pa.gov.br/o-municipio/historia Acesso em 15 de março de 2020.
Imagem 4: imagem atual, da cidade de Anajás.

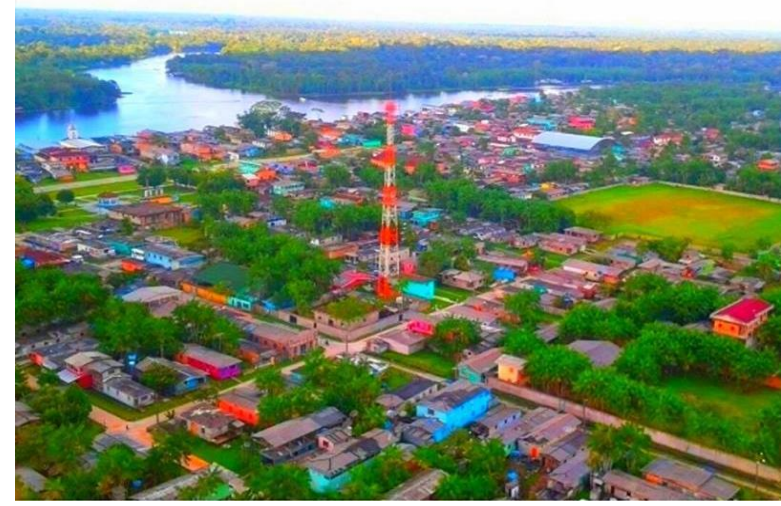

Fonte: https://anajas.pa.gov.br/o-municipio/historia. Acesso em 15 de março de 2020.

\footnotetext{
${ }^{5}$ Festa do menino Deus, tradicional festa religiosa Católica do município, com duração de 10 dias, encerra no dia 25 de dezembro em solenidade ao nascimento de Jesus. Reúne pessoas do município inteiro que participam de missas, procissões, atrações musicais e expressões artísticas cristãs. Há uma mobilização do povo católico, tanto da zona urbana quanto rural, para a realização da tradicional festa. Conta, inclusive, com a participação de pessoas não católicas que contribuem para a preparação desses dias de comemoração. A festa também fortalece a economia e cultura, pois, proporciona mais visibilidade para a cidade.
} 
A região também faz parte da microrregião de Furo de Breves junto com os municípios de Afuá, Breves, Curralinho e São Sebastião da Boa Vista. Esses municípios também integram o Marajó das florestas ${ }^{6}$, uma denominação para compreender parte da região do Marajó em que as características dessa região envolvem paisagens, cultura, modo de vida e a economia. De acordo com Sarraf (2018, p.65) "Sua divisão é realizada em perspectiva geopolítica para marcar diferenças, semelhanças, relações históricas e culturais na constituição da região, pois em termos físicos, esses ambientes estão presentes em toda a Amazônia Marajoara”. Isso quer dizer que essas regiões foram pensadas também no potencial econômico de seus recursos naturais, ou seja, Acho que não pode ficarapelo modo de produção capitalista.

Diante disto, de acordo com Costa, (2015, p.03) "A lógica do capital é a lógica de valorização. A penetração geográfica na Amazônia e a história da região devem ser vistas, portanto, em relação com o processo de expansão do capitalismo, em função da forma, ritmo e volume da acumulação". Os ciclos de exploração que ocorreram no território como a do látex, da madeira, do palmito e açaí, sendo que os três últimos ainda estão presentes, são reflexos das ações do capitalismo em nível planetário, pois as exportações foram e são para atender as expectativas do mercado nacional e internacional.

No Marajó das florestas a exploração econômica está voltada principalmente para o extrativismo. Ainda há resquícios dos ciclos de exploração e expropriação na região e entre elas o domínio de grandes extensões de terras concentradas nas mãos de latifundiários. Dessa forma, a população é esquecida. Os indicadores apontam para esse esquecimento quando revelam os municípios com os níveis mais baixos do Índice de Desenvolvimento Humano-IDH (2010) entre eles estão: Afuá, Anajás, Bagre, Chaves, Portel, e Melgaço, este último sendo o município de maior vulnerabilidade social do Brasil. Todos os municípios supracitados integram o Marajó das Florestas e essa região vem sendo território de disputas e interesses.

Ao longo dos últimos séculos, a região vem sendo interpretada como terra de grandes contrastes: de um lado suas riquezas humanas, arqueológicas e naturais, mas, pelos jogos do político e de interesses particulares de grandes latifundiários e empresários, foi soterrada em pobreza, reverberando diretamente na vida das populações, carentes de oportunidades de trabalho, formação escolar e profissional, além de condições para exercitar seu direito a uma existência digna e cidadã. (SARRAF, 2018, p. 64).

É importante compreender que a visibilidade no Marajó está ligada ao potencial econômico que a região pode oferecer ao mercado, um exemplo disso é a extração do látex. De acordo com Plano de Desenvolvimento Territorial Sustentável do Arquipélago do Marajó (GRUPO EXECUTIVO INTERMINISTERIAL, 2007), o início da extração deu-se no final do século XIX e início do século XX. E durante esse período foi a principal atividade econômica da época, mas que deu margem à migração, principalmente de pessoas oriundas do nordeste do Brasil para trabalhar com o extrativismo nessas regiões.

A exploração do látex representou um período de ascensão do capitalismo e também crescimento econômico. O encontro-choque com as populações tradicionais foi inevitável e isso

\footnotetext{
${ }^{6}$ Corresponde a uma região assim descrita: "Nesse pluriverso, está o Marajó, cravado na foz do rio Amazonas e aberto ao Atlântico. Em sua porção ocidental, conforma-se pelo Marajó das Florestas, nos municípios de São Sebastião da Boa Vista, Curralinho, Bagre, Portel, Melgaço, Breves, Anajás, Afuá e Gurupá, e em sua porção oriental, constitui-se pelo Marajó dos Campos, nos municípios de Chaves, Soure, Salvaterra, Cachoeira do Arari, Santa Cruz do Arari, Muaná e Ponta de Pedras" (SARRAF, p. 64, 2010).
} 
significou conflitos ligados às disputas dos espaços. Harvey (2003) em sua obra, Novo Imperialismo, analisa o capitalismo financeiro como um novo modo de ação capitalista que vem acompanhado do discurso de crescimento econômico contínuo, mas que na verdade os recursos são esgotáveis. O autor sinaliza como o capitalismo age em relação à acumulação primitiva, categoria de análise trabalhada pelo filósofo Karl Marx.

Estão aí a mercadificação e a privatização da terra e a expulsão violenta de populações camponesas a conversão de várias formas de direitos de propriedade (comum, coletiva, do Estado etc.) em direitos exclusivos de propriedade privada; a supressão dos direitos dos camponeses às comuns [partilhadas]; a mercadificação da força de trabalho e a supressão de formas alternativas (autóctones) de produção e de consumo; processos coloniais, neocoloniais e imperiais de apropriação de ativos (inclusive de recursos naturais); a monetização da troca de ativos (inclusive de recursos naturais); a monetização da troca e a taxação, particularmente da terra; o comercio de escravos; e a usura, a dívida nacional e em última análise o sistema de crédito como meios radicais de acumulação primitiva. (HARVEY, 2003, p. 121).

No período de exploração do látex, Anajás se destacou por possuir a maior quantidade de seringueiras (GRUPO EXECUTIVO INTERMINISTERIAL, 2007). A paisagem econômica foi alterada e as relações sociais sofreram muitas modificações com a migração que até afeta o modo de vida ribeirinho. “(...) a partir do século XIX tornou-se um dos maiores produtores de látex do Pará na região das ilhas, constituindo um polo de atração para homens e mulheres em busca de riqueza e trabalho na então emergente e pujante economia gomífera" (ABEP, 2018, p.02).

Assim, agentes econômicos e políticos expropriaram as terras das populações tradicionais de forma ilegal usando a força e a opressão para também utilizarem as pessoas como mão de obra barata para a exportação do látex e de outras atividades ligadas ao território. A cada ciclo foram esgotando os recursos naturais da região, com a mudança da dinâmica de vida, muitas pessoas perderam o sentimento de pertencimento ao lugar, já que até hoje há locais no município que são considerados terras das empresas que um dia se firmaram no município e não como território dos ribeirinhos que sempre estiveram na região.

É importante refletir sobre a privatização da terra e o uso dos recursos naturais que são explorados, pois a extração do látex representou um "novo imperialismo” (HARVEY, 2003) disfarçado de oportunidade de desenvolvimento na região. E mesmo com o declínio da extração do látex, a exploração não parou, surge um novo ciclo de exploração ainda mais nocivo à natureza: a extração de madeira.

No Plano de Desenvolvimento Territorial Sustentável do Arquipélago do Marajó, destacase que "o Estado do Pará é o maior produtor de madeira nativa do Brasil. No entanto, grande parte dessa produção é predatória” (GRUPO EXECUTIVO INTERMINISTERIAL, 2007, p. 42). Diz ainda que "os municípios de Anajás, Bagre, Breves e Portel são responsáveis por 91\% da extração de madeira em tora do Arquipélago do Marajó" (idem, p. 44), e que existe a necessidade de regularização de terras no arquipélago, porque há muitos latifundiários que, de forma ilegítima, expropriaram muitas extensões de terras, principalmente as empresas com o intuito de exploração extrativista na região. Como meta para o município de Anajás, estabeleceram a regularização das terras por compreender que essa região é uma das mais afetadas pela exploração desordenada dos recursos naturais assim como pela expropriação de terras.

Nota-se que a acumulação por despossessão nessa região é muito expressiva, ou seja, uma 
expropriação, posses de terra e de recursos naturais ilegítimas que vai se manifestar de diversas formas, mas, principalmente pela privatização do território (HARVEY, 2003).

A privatização, conclui Roy, é essencialmente 'a transferência de ativos públicos produtivos do Estado para empresas privadas. Figuram entre os ativos produtivos os recursos naturais. A terra, as florestas, a água, os ar. São esses os ativos confiados ao Estado pelas pessoas a quem ele representa (...). Apossar-se desses ativos e vende-los como se fossem estoques a empresas privadas é um processo de despossessão bárbara numa escala sem paralelo na história'. (HARVEY, 2003, p.133).

Um dos exemplos mais recentes da despossessão no município de Anajás foi a tentativa de leiloar parte das terras pela empresa madeireira TREVO/BRUMASA, negado pelo Ministério Público Federal do Pará, em 2016. Esses acontecimentos estão presentes ao longo da história do município, na maioria das vezes, despercebidos pelos próprios afetados, como a população ribeirinha. No entanto, o mercado de terra e as disputas na região permanecem até hoje. O esforço em problematizar o processo de colonização, consiste no fato da negação de um processo histórico de exploração desencadeado pelos conflitos de interesses que prevalecem até hoje. Esses processos que ocorreram desde a colonização, atendendo aos interesses de um capitalismo monopolista baseado na exploração e beneficiamento de matéria-prima para o mercado internacional numa lógica imperialista.

E posteriormente, com a inserção do neocolonialismo, envolvido por um capitalismo mais moderno e com potencial de exploração maior ocasionado pelo processo de industrialização. São processos que sinalizam a dinâmica política, social e econômica a cada nova ação do capitalismo e a cada modelo adotado por ele. $\mathrm{O}$ atual modelo neoliberal corresponde "a um conjunto de políticas econômicas como a defesa de um Estado mínimo, a austeridade fiscal nas contas públicas, defesa intransigente da propriedade privada e do livre mercado" (KAYSER, 2019). Assim, esse modelo adota um conjunto de políticas com características de "visão de progresso" pautado no desenvolvimento econômico. A partir disto, são propostas medidas econômicas como implantações de empresas privadas para a exploração dos recursos naturais.

O modelo econômico desenvolvimentista que ocorreu na Amazônia significou um amplo processo de acumulação de capital, acompanhado do discurso que era necessário sair do "atraso" somente com desenvolvimento econômico em grande escala seria capaz de oferecer, ou seja, um processo de industrialização acelerado com tecnologia de ponta. A partir disso, surge o neodesenvolvimentismo, vertente do desenvolvimentismo, isso porque, seguem os aspectos de acumulação de capital e inserção de empresas privadas para a exportação de matéria prima (SILVA, 2015).

Visto isso, a Amazônia ainda continua sendo palco para as atividades de mercantilização, como exemplo, temos as usinas hidrelétricas, instalações de empresas para a exploração de madeira, palmito, alumínio, entre outras, assim, (idem, 2015, p. 433), "tal modelo baseia-se na articulação entre a exportação de produtos primários (agrários-extrativistas) e na realização de grandes obras de infraestrutura". Com isto, surge um modelo, que atende essas expectativas, o neoextrativista, que segundo Santos e Milanez (2013), o neoxtrativismo, aparece como uma proposta de modelo econômico de responsabilidade do Estado em articular medidas para o crescimento econômico e para desenvolvimento do país, desenvolvimento este, estritamente econômico, acompanhados de medidas que deveriam minimizar os impactos do processo de exploração. 
Ainda para os referidos autores, o neoextrativismo se apresenta como um alargamento derivado das atividades extrativistas, só que amparados institucionalmente e mais intensificado, isto é, “[...] conceito cunhado para definir um conjunto de estratégias de desenvolvimento ancoradas em um grupo de setores econômicos que removem um grande volume de recursos naturais para comercialização após nenhum ou quase nenhum processamento" (SANTOS; MILANEZ, 2013, p.03). O conjunto dessas mudanças serviram para permanecer a acumulação primitiva, fundamental para atender a reprodução social do capital mantendo a concentração de lucros do mercado de terras e da expropriação dos territórios.

\section{TERRITÓRIO E IDENTIDADE EM ANAJÁS: RELAÇÕES DE PODER, DISPUTAS E CONFLITOS SOCIOMABIENTAIS}

Muito além de uma delimitação de terras, o território se constitui como dimensão histórica, social e política (SPOSATI, 2013). Isso porque, revela modos de vida, de saberes, de trabalho, de relações humanas e dá sentido de identidade individual e coletiva. A construção da identidade se estabelece a partir das relações humanas, da relação com a natureza, espaço, poder, interesses e disputas (SAQUET e SPOSITO, 2008). Desse modo, para compreender a identidade em Anajás é necessário compreender primeiro a dimensão em que o território está inserido, assim como a territorialidade e a desterritorialização para fazer o movimento critico reflexivo com as particularidades apresentadas pelo território de Anajás (idem).

É nesse contexto que para Sposati (2013, p. 07) "o conceito de território, no singular ou plural, refere-se a uma concepção dinâmica, tanto do ponto de vista geográfico, como histórico, político e sócio - relacional", isso quer dizer que território e territorialidade não devem ser pensados como algo inerte, tão pouco como espaço desvinculado da totalidade (histórica, social, política) mesmo que possua suas particularidades.

Território e territorialidade segundo Sposati (2013) devem ser pensados como espaço e movimento de vida. A partir da sua dinâmica e das relações sociais e de seus interesses comuns, cria-se um vínculo com os atores envolvidos nesse espaço, ou seja, a territorialidade, entretanto, a autora acrescenta que também a partir desses interesses comuns pode ocorrer a desterritorialização, isto é, uma quebra de vinculo ligado principalmente pelas correlações de forças e de disputas que há no território, esse caráter está integrado à dimensão política que envolve o território.

Para Raffestin (2008, p.31) "produção territorial sempre tem um ponto de partida que nunca é ileso das ações do passado. O processo territorial desenvolve-se no tempo, partindo sempre de uma forma precedente, de outro estado de natureza ou de outro tipo de território". Nessa perspectiva é possível compreender o porquê da dimensão histórica no processo de construção do território, e como os conflitos presentes em Anajás estão ligados principalmente ao modo de produção capitalista que trouxe como consequência a privatização da terra e exploração dos recursos naturais. Por isso não é possível dissociar território e história, pois é extremamente necessário para compreender a realidade em que os indivíduos estão inseridos, assim como os problemas que ocorrem.

Isso ajuda a entender o processo de desterritorialização desse lugar ligados aos ciclos de exploração que se estabeleceram e se estabelecem nesse território. $\mathrm{Na}$ medida em que as relações de poder fizeram e fazem com que as relações sociais desse lugar fossem determinadas de acordo com os interesses econômicos de um grupo, ou seja, dos latifundiários (dimensão e 
exploração), e não dos poderes públicos, contribuiu para um processo de desterritorialização devido à ausência cada vez maior de ações voltadas a garantia de direitos e promoção da cidadania.

É importante ressaltar que embora os ribeirinhos utilizem os recursos naturais como meio de subsistência, moradia e mesmo o cuidado com a preservação da área de uso, ainda há grande extensões de terras que estão concentradas no poder de famílias, e assim as posses de terras são passadas de geração em geração sem que haja preocupações em proporcionar a população ribeirinha a legalização das terras, criação ou efetivação de políticas que atendam a necessidade desses indivíduos, principalmente a regularização de terra.

O Plano de Desenvolvimento Territorial Sustentável do Arquipélago do Marajó (GRUPO EXECUTIVO INTERMINISTERIAL, 2007) sinaliza a importância da regularização das terras, como forma de reconhecer o direito as populações tradicionais do município. Com efeito, poucas ações vêm ocorrendo no sentido de efetivação da legalização das terras das populações e comunidades tradicionais. O que se percebe é um esquecimento, cada vez maior, da população e das representatividades para esse direito.

Um dos entraves presentes é o fato de alguns dos agentes capitalistas responsáveis pela exploração do território tornam-se também agentes políticos. Essas famílias que se envolvem com as questões da exploração do território e assumem cargos políticos, muitas vezes representam seus próprios interesses, o que acaba por influenciar as tomadas de decisão que deveriam atender às demandas sociais da população ribeirinha, mas que por não haver participação popular esses interesses acabam se sobressaindo.

Exemplo disso é a não legalização de algumas empresas que atuam hoje no município com a extração dos recursos naturais. Não há preocupação na fiscalização das atividades extrativistas e nos impactos que elas podem desencadear a essa população, como conflitos ambientais. Não há atenção para áreas ambientais que necessitam de proteção, assim como para as próprias populações tradicionais.

Os conflitos ambientais que hoje são vividos em Anajás se configuram em conflitos velados, em que a população não se percebe em meio a correlação de força que é exercida pelos agentes capitalistas e por agentes políticos que não tem interesses em atuar na efetivação de direitos. As estratégias para exploração extrativista se apresentam como única alternativa de subsistência e não oferecem seguro aos trabalhadores, nem condições dignas de trabalho. E, quando não há mais trabalho nos espaços a serem explorados, as estratégias adotadas volta-se para inserção em programas de distribuição de renda, como o Bolsa Família, que deveria ser para auxiliar a renda familiar, mas em muitos casos acaba por ser a única renda da família.

Pouco se efetiva a representatividade da população nos espaços de tomada de decisão ou mesmo na efetivação das políticas públicas e ações que representam a realidade dos ribeirinhos. Percebe-se que não há interesse e tão pouco estratégias de participação popular. A ausência de um CRAS - volante é um exemplo disso. O município conta com apenas um CRAS, a maioria da população encontra-se na parte rural e muitas delas em áreas de difícil acesso. Diante disso, seria fundamental a presença de equipes volante, pois para muitos ribeirinhos a dificuldade de acessar os serviços básicos é gigantesca, principalmente pela distância e dificuldades econômicas.

Não se verifica algum trabalho em rede com associações e com os próprios líderes das comunidades. O município conta com uma Associação dos Trabalhadores Rurais, uma Associação dos Pescadores, Sindicato dos Trabalhadores em Educação Pública (SINTEPP) e a 
ainda, com a Empresa de Assistência Técnica e Extensão Rural (EMATER) que tem uma experiência na área de formação e qualificação. É imprescindível o envolvimento dessas instituições como estratégia de gestão das políticas públicas, pois as associações e líderes das comunidades estão mais próximos à realidade de comunidades e povos tradicionais e compreendem o modo de vida da população ribeirinha.

Além disso, as poucas estratégias pensadas para promoção e garantia de direitos das populações tradicionais, muitas vezes, sofrem entraves das próprias administrações públicas que deveriam fomentar o fortalecimento da população. Um exemplo é o baixo número de conferências realizadas, subutilizando um importante instrumento de planejamento, controle e gestão das políticas públicas, além de ampliar a formação e informação das populações ribeirinhas no sentido de potencializar a participação social, o debate democrático e o atendimento de demandas. Todas essenciais para a afirmação do sujeito da política e sua territorialidade

Outro aspecto a se destacar é a atuação de empresas/instituições que ainda desenvolvem ou querem desenvolver algum projeto objetivando uma produção sustentável para a região e não conseguem mantê-lo, ou mesmo, nem se quer são efetivados, principalmente por não dá o retorno financeiro que as fábricas conseguem, como pagar um valor maior que as associações podem pagar pela matéria prima.

Isso ocorre também com as audiências públicas, com a formação de conselhos que mesmo contando com a participação de membros da comunidade local, não conseguem manifestar suas demandas e dificuldades. Isso porque, muitos conselhos que são formados meramente para atender requisitos, o que acaba tornando-os burocráticos e tecnicistas. Como consequência, os conselhos não conseguem cumprir a sua função primordial que é de contribuir para ações que serão realizadas no município, na prestação de conta dos recursos que foram utilizados, além de propor alternativas que melhor dizem respeito à realidade da comunidade local, sempre engajado com interesses coletivos sem interesses individuais.

Nesse contexto social e político, marcado por essa relação de poder, as pessoas mais vulneráveis do município são as que mais sofrem as consequências, principalmente as ribeirinhas, já que mais da metade dos munícipes de Anajás encontram-se na zona rural. As terras que são usadas para a extração de palmito, açaí e madeira, na maioria das vezes, acontecem de forma desenfreada, o que não proporciona melhorias de vida aos extrativistas e suas famílias. O que há é uma precarização do modo de vida, pois pelas atividades que são realizadas de forma exploratória leva ao esgotamento de recursos, se algo não for pensado em relação à preservação desses recursos a consequência é a escassez cada vez maior.

Essa escassez significa principalmente riscos às populações mais vulneráveis, isso porque pode afetar os meios de subsistência dessas populações. Além do mais, é muito difícil a política pública suprir demandas deixadas pelo processo de exploração total de um território, pois as consequências são catastróficas. As políticas públicas são extremamente necessárias para a preservação dos territórios objetivando a não destruição da sociedade e da natureza.

Sabe-se que a relação com o território é baseada também na relação (i)materialidade com a natureza, por isso a degradação desta, gera impactos incalculáveis aos humanos. A destruição não se apresenta só no campo da materialidade, com a retirada da matéria-prima, mas na subjetividade também, na representatividade que o território proporciona às populações mais antigas. A mercantilização dos recursos naturais pode representar aniquilamento a uma população tradicional, ou várias. E esse fato é histórico, sempre atrelados a expropriação do que pertence as populações tradicionais. 
Com Raffestin este tema é problematizado: "Devemos ter consciência de que a transformação da atividade humana e por consequência, dos processos de territorialização corresponde a outro modo de compreender as coisas degradadas na natureza" (2008, p.25). Para o autor, esse "modo de compreender" significa que a cada mudança e a cada ação humana no território acarretará em consequências que determinaram a construção de territorialidade. Como a ação do homem no município de Anajás desde sua constituição foi pensada apenas como potencial exploratório e a consequência disso hoje aparecem nas múltiplas expressões da questão social reveladas no baixo Índice de Desenvolvimento Humano - IDH (IBGE, 2010), baixa escolarização, sistema de saúde precário, exploração sexual infantil, precarização do modo de vida das populações ribeirinhas e principalmente pela desigualdade social.

Essa realidade é vista em todo o território de Anajás tanto na zona urbana quanto rural. Para Raffestin "não é somente o homem que tem uma vida precária, mas também os territórios por ele criados” (2008, p.32). Isso quer dizer que a construção de identidade individual e coletiva que se dá a partir de um território é também expressões sociais que se estabelecem nesses espaços, sejam elas relações fragilizadas pelo processo de exploração, supressão do direito ou potencialidades dessa população, todos os fatores e dinâmica envolvidos nesse processo afetam diretamente o modo de vida da população ribeirinha e contribui para precarização de suas territorialidades.

A malária, por exemplo, aparece como uma expressão gigantesca dessa consequência. O município é o que apresenta o maior número de casos da doença e poucas ações foram pensadas para região no sentido de amenizar esses impactos. As ações que foram efetivadas apenas conseguiram amenizar minimamente a doença, mas Anajás continua sendo o município com o maior número de casos de malária. Isso é consequência das atividades de exploração e o precário sistema de saneamento do município, que segundo o Plano de Desenvolvimento Territorial Sustentável do Arquipélago do Marajó (GRUPO EXECUTIVO INTERMINISTERIAL, 2007), é um dos piores do Arquipélago do Marajó.

Para fazer um comparativo da situação dos munícipes em relação à malária, em 2010 o município entrou em estado de calamidade pública, nesse mesmo ano, segundo Canellas (2010), havia "25 mil habitantes e 10 mil casos de malária só na primeira metade do ano. É quase impossível encontrar alguém que não tenha sido contaminado, pelo menos, uma vez" afirma o autor. No de 2017 o município ficou entre as 10 cidades com maiores casos de malária, foram 5.585 casos registrado da doença. (ROSSI, 2018).

No contexto Marajó, o Plano de Desenvolvimento Territorial Sustentável do Arquipélago do Marajó (GRUPO EXECUTIVO INTERMINISTERIAL, 2007) já apontava para a necessidade do combate à malária no município e enfatizando a importância de ações nas questões de saúde pública, revelando altos índices da doença nessa região.

Por isso, a compreensão do território é importante para que discussão de possíveis riscos de acordo com a dinâmica que ocorre na construção do território e toda sua territorialidade. Além do mais, é possível ainda compreender a realidade e possíveis alternativas que, de fato, poderiam ser tomadas no sentido de contribuir para o acesso e efetivação das políticas públicas no município, principalmente as populações ribeirinhas, pois são as mais afetadas pela ausência delas.

De acordo com Raffestin (2008, p.26), “A cada mudança de estado, técnica e, por consequência, a cada mudança da territorialidade, a produção territorial é alterada e os problemas a serem enfrentados com relação ao ambiente são mais diversos". Para a população ribeirinha 
de Anajás, os problemas ambientais podem significar riscos, assim como extermínio caso não sejam impedidos - como é o caso das atividades madeireiras - e, ao mesmo, se faz necessários programas de geração de trabalho e renda adequados e construídos coletivamente com as populações ribeirinhas. Dessa forma, essas populações que vivem da pesca artesanal e do roçado devem ter seu direito reconhecido de forma legal, que é o direito à terra. Os próximos itens do artigo discorrem sobre esta realidade.

\section{COMUNIDADES TRADICIONAIS E O DIREITO E TERRITORIALIZA- ÇÃO DAS POLITICAS PÚBLICAS}

A problematização das políticas públicas é essencial para a realidade das comunidades ribeirinhas em regiões como Marajó. A territorialização dessas políticas exige respeito às diversidades. Segundo Viana e Baptista (2009 apud DALFIOR et al., 2015, p.284) "é possível afirmar que falar de política pública é falar de Estado, de pacto social, de interesses e também de poder, envolvendo recursos, atores, arenas, ideias e negociações". Dessa forma, elas representam a responsabilidade e papel do Estado em um território, como formulações de políticas públicas que podem ser econômicas, sociais, ambientais, dentre outras. Sendo mediadas por administrações públicas, instâncias, setores com o objetivo de gerenciar e também criar novas políticas que contribuam para a melhoria de vida da população.

Dito de outra maneira, as Políticas públicas são a totalidade de ações, metas e planos que os governos (nacionais, estaduais ou municipais) traçam para alcançar o bem-estar da sociedade e o interesse público. É certo que as ações que os dirigentes públicos (os governantes ou os tomadores de decisões) selecionam (suas prioridades) são aquelas que eles entendem serem as demandas ou expectativas da sociedade. (SEBRAE, p.05, 2008).

Percebe-se como as políticas públicas correspondem à centralidade dos serviços para proporcionar qualidade ao modo de vida. Na realidade de Anajás, as potencialidades de exploração dos recursos naturais do território não são voltadas para a geração de bem estar para sociedade local. Percebe-se que os agentes capitalistas (madeireiras, latifundiários, extração do palmito e empresas de cosméticos) concentram os dividendos com a produção da riqueza gerada. A mercantilização da natureza não condiz com a realidade das populações e comunidades ribeirinhas. E o Estado, como mediador das atividades, opta por favorecer às relações desiguais e assimétricas entre os agentes econômicos e atores sociais.

Para Raffestin (2008), o território se constitui também como espaço de "matéria prima" para que a partir da ação do homem sejam criadas diversas manifestações, sejam elas culturais ou novas formas de trabalho. Esse processo de transformação capitalista das matérias primas em mercadoria no município não conta com a participação do Estado e gestão municipal como mediadores para uma atuação responsável e sustentável. O que há é a atuação dos agentes capitalistas de forma livre, estabelecendo aproximações com a população ribeirinha, em que essa aproximação por, muitas vezes, vem resultando em exploração dos recursos das áreas ocupadas, quase sempre acompanhadas da falácia de melhores condições de vida.

Nesse debate, o encontro território, meio ambiente e políticas públicas aciona uma importante percepção da realidade social e dos modos de vida diferenciados, como discute Matos: 
Os territórios são ambientes nos quais se desenvolvem conflitos e processos que dão sentido espacial e econômico à história social da ocupação humana. Representam desafios à gestão governamental, especialmente se pensada de forma integrada e participativa. Entretanto, nos diagnósticos e programas de desenvolvimento econômico de muitos dos planos governamentais levados a cabo durante o século XX, foi comum priorizar os investimentos setoriais e ignorar o espaço como categoria de análise. (MATOS, 2008, p. 141)

Ausência das políticas públicas em um município e/ou a sua minimização se dá em decorrência da conjuntura política em que o capitalismo está inserido, atualmente presencia-se o neoliberalismo. Sposati (2013, p.10) diz que "esta constatação leva ao entendimento de que o neoliberalismo, no Brasil, não opera, propriamente, o desmonte social, mas o travamento das condições necessárias para a efetivação dos serviços”. Isso quer dizer que as políticas públicas, nesse cenário, serão cada vez mais ausentes devido a criação de barreiras impostas pelo capitalismo articulados com agentes políticos, responsáveis pelas tomadas de decisão e utilização dos recursos para município.

Com isso, as populações ribeirinhas, quilombolas e indígenas são as que mais sofrem com os impactos dessa ausência. Sobre o tema, comentam Sá e Fialho Nascimento (2012, p.8): “O Estado, como gestor das políticas públicas de atendimento à população, apenas ensaia ações de caráter paliativo. $\mathrm{Na}$ maioria das vezes suas ações sequer incorporam uma política de atendimento às populações atingidas pelos grandes projetos”. Assim, os problemas sociais, econômicos e políticos de Anajás, não são exclusivos do município e tão pouco uma realidade isolada, mas parte das relações sociais e do modo de produção capitalista que se estabelecem a partir do trabalho, conectada ao mundo.

O Estado, como responsável pela garantia dos direitos sociais, deveria desenvolver ações que de fato atendesse às necessidades dessa população, mas o que ocorre é que são elaboradas estratégias para camuflar os problemas que ocorrem como parte das relações assimétricas existentes no município. As correlações de forças presente se dão de um lado, os latifundiários e madeireiros, e recentemente, empresas ligadas a exportação de óleos para a produção de cosméticos, do outro lado às instituições religiosas católicas, atuando com denúncias, participação nos espaços coletivos, mas com uma atuação limitada em razão do contexto político que, por sua vez, coopera para baixa discussão sobre os problemas sociais.

Essa falta de compreensão dos problemas que ocorre no município é consequência das estratégias capitalistas de não criar espaços de discussões sobre políticas públicas na região para favorecer à apropriação dos recursos presente no território. No entanto, há ações da Igreja para ampliar o conhecimento da realidade social. Nas imagens abaixo, Dom Evaristo Pascoal Spengler, bispo prelado da Prelazia de Marajó, em visita à Paróquia Menino Deus de Anajás, no período de 08 a 22 de setembro de 2019, também visitou comunidades em seis setores do interior do município, com o intuito de conhecer a realidade de cada comunidade. 


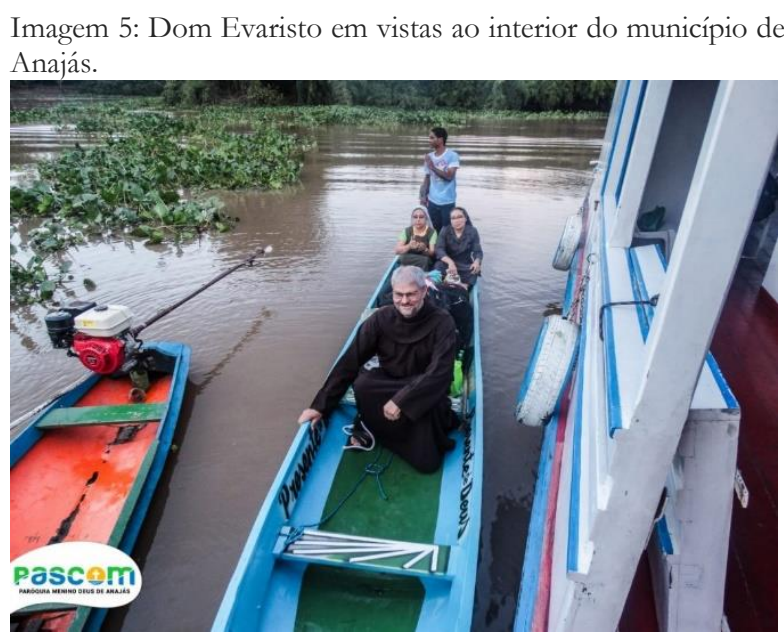

Fonte: http://cnbbn2.com.br/prelado-do-marajo-realizou-visita-pastoral-a-paroquia-de-anajas/. Acesso em 18 de março de 2020.
Imagem 6: comunidade aguardando a chegada de Dom Evaristo para a visita a comunidade.

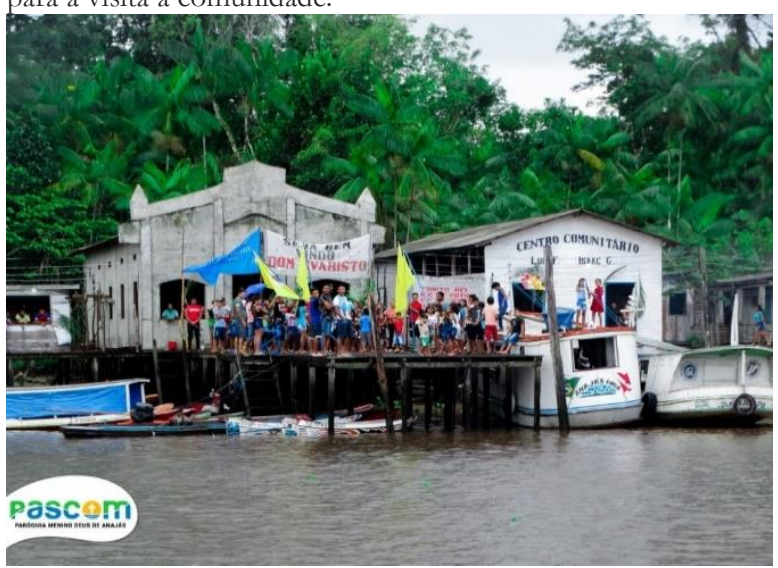

Fonte: http://cnbbn2.com.br/prelado-do-marajo-realizou-visita-pastoral-a-paroquia-de-anajas/. Acesso em 18 de março de 2020.

A atuação das instituições religiosas no território converge para ações de mobilização entorno da conquista de direitos, além de acesso à informação e mobilização social. Aproximação das ações da Prelazia com outras entidades tem objetivo de garantir para a população de condições dignas, qualidade de assistência e fomento às potencialidades. E, principalmente, garantir a preservação da vida das populações tradicionais e isso significa preservar os espaços, o território.

A Constituição Federal assegura que: "Todos têm direito ao meio ambiente ecologicamente equilibrado, bem de uso comum do povo e essencial à sadia qualidade de vida, impondo-se ao Poder Público e à coletividade o dever de defendê-lo e preservá-lo para as presentes e futuras gerações" (CF, art. 255, p.177). A exploração desenfreada entra em conflito aberto ao direto constitucional. Por outro lado, a exploração para o mercado e expropriação das terras das populações tradicionais não são alternativas para proporcionar ambiente equilibrado, muito pelo contrário, a desigualdade torna-se a principal expressão dessa relação.

Contudo, há de reconhecer que atuação de líderes religiosos tem somado no processo de luta em Anajás, até mesmo para viabilizar a participação dos sujeitos da política, visto que é indispensável à participação popular, pois é a principal forma de luta e enfrentamento das violações de direito e dos conflitos por terra.

\section{4 É POSSÍVEL FALAR DE RESISTÊNCIA EM ANAJÁS?}

Os movimentos sociais, as formas de organização social de grupos socialmente invisibilizados e os enfrentamentos diversos em curso na Amazônia são fruto dos processos sociais de resistência e luta política por direitos socioterritoriais. Em cada região da floresta, as histórias, os instrumentos e as formações coletivas de reagir e construir acenam outras alternativas de vida e produção. Importa mencionar que mesmo nas especificidades de lutas e enfrentamentos, há uma centralidade que converge para afirmação das diversidades dos povos da Amazônia diante dos modelos predatórios e genocidas do capital.

As cadeias produtivas de palmito, óleo, açaí e madeira mapeiam o território do capital no município, perfazendo o controle funcional do espaço de produção, agenciado pelo Estado 
que legitima tais ações. Nessa perspectiva de escala governamental, portanto, ferramenta de intervenção pública, etnia, identidade e tradição são negados e invisibilizados. As cartografias oficias são relações de poder do ordenamento territorial que padronizam, homogeneízam e esvaziam todas as outras formas de vida e formas de reprodução social da vida, como uma demanda da agenda neodesenvolvimentista/neoextravita. Além do mais, é importante pontuar que junto ao modelo neodesenvolvimentista/neoextravita acompanha o discurso de sustentabilidade para ações de exploração e mercantilização. É notório que esse processo tem desencadeado destruição ao modo de vida das populações mais antigas. Para Silva:

O aprofundamento do processo de mercantilização da natureza, através da biopirataria, da grilagem, da pilhagem dos recursos naturais e instaurações dos grandes empreendimentos e atividades poluidoras em geral, tem produzido impactos a saúde e o modo de vida das populações mais atingidas, especialmente os denominados povos ou comunidades tradicionais, acentuandose, assim, os conflitos socioambientais. (SILVA, 2015p.430).

A autora enfatiza que, embora os discursos voltados para as atividades de sustentabilidade e preocupações com o meio ambiente, dentro desse modelo econômico, não há efetividade na prática. O que se evidencia, na maioria dos projetos que se voltam para o desenvolvimento econômico em massa, são os conflitos socioambientais e a desigualdade cada vez maior, decorrente das atividades voltadas à mercantilização. Em Mathis et al, o debate é reforçado.

O ideário neodesenvolvimentista difundido no Brasil, principalmente, nas primeiras décadas dos anos 2000 não alterou o lugar da Amazônia na divisão internacional e nacional da exploração do trabalho. No caso específico do Pará, espaço por excelência de commodities na região, ampliase o investimento no setor industrial iniciado desde os anos 1980, que tem como carros-chefe as megaindústrias do setor minerometalúrgico, sendo o maior complexo da América Latina no beneficiamento de alumina e produção de alumínio. (Mathis et al., 2016, p.246).

Mathis et al. (2016) apontam para as intensificações de exploração que vem ocorrendo na Amazônia, se intensificando no estado do Pará, destaca para os efeitos como, empregos informais, subempregos, desterritorialização dos povos e comunidades mais antigas, conflitos socioambientais, aniquilamento das populações por disputas de terras e desigualdade social cada vez mais expressivo. As políticas sociais no modelo neodesenvolvimentista tiveram papel de destaque, pois aparecem nos discursos como alternativas de reduzir as desigualdades sociais, mas acabou por tornar as políticas sociais focalizadas.

Ainda, sobre o papel das políticas no modelo econômico neodensenvolvimentista, é importante destacar os discursos que vem ocorrendo, ou melhor, as estratégias adotadas para a eliminação dos sujeitos da política, como a necropolítica. Se as políticas focalizadas se configuram como políticas que classificam as pessoas em situação de vulnerabilidade, não permitindo fomentar as potencialidades humanas dos sujeitos. A necropolítica se apresenta no sentindo de eliminação dos sujeitos da política. Isso porque, “em termos teóricos, a necropolítica demarca uma alteração na forma com que são exercidas as noções de soberania e poder, que passam a ser estruturadas a partir do princípio de quem pode viver e quem pode morrer" (KAYSER, 2019), provocada pela crise que o capital desencadeia.

Nessa conjuntura, as populações tradicionais sofrem sérios riscos, pois seus espaços foram e vem sendo apropriados pelo neoextrativismo. As atividades de superexploração em territó- 
rios de comunidades e povos tradicionais são incompatíveis com os modos de vida dos grupos socialmente diferenciados. O racismo ambiental e a injustiça social usurpam a dignidade desses grupos colocando suas vidas em risco na medida em que a preservação da natureza representa a preservação da vida de comunidades e povos tradicionais. $\mathrm{O}$ aniquilamento dessas populações e as violências por elas sentidas remontam ao processo colonial e se reatualiza na sociedade contemporânea.

O capital tem grande papel sobre isso, principalmente por mover os interesses econômicos, em que a cada processo de exploração vai se sofisticando a forma de expropriação e aniquilamento da população tradicional. Assim, os problemas que ocorrem em Anajás se apresentam a partir desses acontecimentos, integrando o espaço de disputas. Todos esses ciclos de exploração são consequências das atividades de exploração para o crescimento econômico e são observados no município, e as desigualdades sociais tornam-se cada vez mais expressivas.

A territorialização social das lutas sociais se dá no ambiente do neoextrativismo, sustentabilidade e necropolítica. Todos esses aspectos promovem destruição, desastres, desestruturação socioambiental. Por outro lado, mobiliza sujeitos políticos para construir formas de enfrentamento coletivo, entendendo que a conflitualidade do território pressupõe compreender qual o lugar da valorização das vidas das florestas e das águas presentes nas disputas. Por outro lado, a resistência desses povos é histórica e coberta de estratégias, saberes e mudanças.

A resistência dos índios Inajás à colonização talvez seja o maior marco da resistência em Anajás da população nativa. Atualmente, a correlação de forças presente no município demanda uma reação mais organizada e coletiva por parte da sociedade civil na direção da luta por direitos sociais. Não obstante as ações em curso, promovidas pela Igreja, associações de moradores, colônia de pescadores e entidades sociais, ainda há problemas na organização social mais coletivizada no município. Esse fato permite-nos compreender o porquê desse quadro. De certa forma, há muito desconhecimento sobre a origem da população, sobre a discussão de identidade e direitos, isso resulta das estratégias de negação impulsionadas pela conjuntura política neoliberal que visa fragilizar pessoas questionadoras, que apresentem alternativas para a preservação do meio ambiente. Com o desconhecimento de seus direitos, a população tende a aceitar as situações precárias que são impostas de diversas formas, como trabalho informal, baixo custo de matéria prima explorada no território e má qualidade dos serviços básicos à população.

Contudo, há de reconhecer que atuação de líderes religiosos é crucial no processo de luta em Anajás, até mesmo para viabilizar a participação dos sujeitos da política, visto que, é perceptível a atuação de líderes ligados à Igreja em espaços políticos de discussão no território, inclusive, a disponibilizar espaços para promover esses debates. Dom José Luiz Azcona, Bispo Prelado Emérito do Marajó-PA, é um dos exemplos de como a atuação religiosa tem sido importante para as questões sociais dos ribeirinhos. O bispo denuncia desde $2006^{7}$ a exploração sexual de crianças e adolescentes e o tráfico internacional de mulheres do Marajó, foi ameaçado de morte por isso, mas não o impediu de continuar a falar sobre os problemas que ocorrem em todo o Marajó.

O bispo prelado do Marajó, Dom Evaristo Pascoal Spengler, também tem, tido importantes inserções para conhecer a realidade de cada comunidade e suas dificuldades e conversar sobre

${ }^{7}$ Informações extraídas do documento de Comissão Parlamentar de Inquérito da Assembleia Legislativa do Estado Pará (ALEPA, 2010). 
o Sínodo da Amazônia ${ }^{8}$, em que a sociedade é chamada a discutir sobre as ameaças que pairam sobre os povos indígenas e o meio ambiente na Amazônia.

Somado a isso, a participação de líderes religiosos no município, como padres e freiras, tem se tornado um grande aliado na resistência da população, principalmente das comunidades ribeirinhas, através de visitas com discussões sobre as principais necessidades desses, permitindo assim uma aproximação das comunidades com a instituição religiosa e aproximação de instâncias como ministério público, audiência pública, com o intuito de legitimar as violações que ocorrem no território exigindo respostas para a população.

A atuação das instituições religiosas se apresenta, principalmente, com denúncias via Ministério Público, esse tem sido um dos principais instrumentos utilizados por essas instituições como forma de enfrentamento das injustiças sociais. Trata-se de confrontos políticos, entre instâncias religiosas e legislativas, que acabam por revelar o quanto é necessário à participação popular para evitar a dilapidação do patrimônio público, nesse caso, os recursos naturais. Esse processo de luta e defesa das terras tem despertado, a cada ano, interesses da população, pois os recursos estão a cada dia mais escassos.

A disputa se torna não somente por defesa da natureza, mas uma luta por sobrevivência, visto que parte da população entende a importância dos recursos para subsistência, como exemplo o açaí, muitas pessoas têm preservados grandes áreas para o cultivo do fruto, pois nas safras ${ }^{9}$ torna-se o principal meio de renda dos ribeirinhos. A compra do açaí é feito em grande parte por geleiras ${ }^{10}$ oriundas de outros municípios e, até mesmo, de outros estados para comprar o açaí dos ribeirinhos.

Nesse contexto, embora a complexidade da conjuntura política favoreça atualmente agentes capitalistas no território, há possibilidades de fortalecer grupos de resistência em associações de ribeirinhos e colônia de pescadores. As aproximações das pastorais da Igreja com a população ribeirinha estão se intensificando, assim como a participação nas discussões sobre poder político, direito e justiça social e retrocessos. Tais práticas abrem espaço para ampliação com tensões e contradições que compõem o campo de forças políticas em (re)construção. Isto é construção de territorialidade, participação comunitária por interesses coletivos.

Outro ponto a destacar é a tentativa de grupos de ribeirinhos se unirem para a criação de cooperativas agroecológicas, objetivando trabalhar com atividades extrativistas que não agridem ao meio ambiente, resgatando práticas antigas como a extração de óleos como patauá, andiroba e murumuru, como demonstração de atividades que podem ser pensadas para a subsistência e preservação das práticas dos ribeirinhos. Essa organização da população ribeirinha representa a resistência de um povo que apresentam alternativas de modo vida que não a da exploração desenfreada que vem correndo no território de Anajás.

\section{CONSIDERAÇÕES FINAIS}

A compreensão da dimensão territorial de Anajás permite uma aproximação com a reali-

\footnotetext{
8 O Sínodo para Amazônia foi uma resposta do Papa Francisco à realidade da Pan-Amazônia. De acordo com Francisco, “o objetivo principal desta convocação é identificar novos caminhos para a evangelização daquela porção do Povo de Deus, especialmente dos indígenas, frequentemente esquecidos e sem perspectivas de um futuro sereno, também por causa da crise da Floresta Amazônica, pulmão de capital importância para nosso planeta” (REPAM.ORG).

${ }_{9}$ O período de colheita do fruto varia de acordo com cada região.

${ }^{10}$ Grandes embarcações que congelam o açaí para levar a longa distância. No município, o açaí tem como destinos principais, cidades como Belém, capital do estado do Pará, e Macapá, capital do estado do Amapá.
} 
dade social dos sujeitos da política e como ocorre o enfrentamento dos problemas sociais a partir das mudanças no território. De igual importância, a abordagem a identidade cultural do município e os conflitos que se dão a partir das relações de poder revelam a assimetria a acerca do direito e acesso às políticas públicas.

O repertório de violências e violação de direitos tem aparato financeiro e politico é estrutural para a atuação de atividades neoextrativistas atreladas ao Estado. Não obstante as adversidades de infra-estrutura e financeira, há iniciativas embrionárias para compreender e interver sobre a realidade da subalternidade de grupos sociais que não estão no foco das políticas públicas. Nesse sentido, a disputa entre o lucro da destruição da floresta contrasta com a ampliação da desigualdade social, da negação dos direitos e reforça-se a visão operante de uma elite econômica e política. Essas ações guardam intencionalidade com os projetos de desenvolvimento executados por uma política de padronização das relações sociais, políticas e econômica para atender a dinâmica de acumulação do capital, concentração da terra e riqueza e voltada para o mercado externo.

As lutas de resistência e atuação crítica de organizações e movimentos sociais tensionando o campo de conflitos e contradições. E, para as reflexões discutidas no artigo, reside aí o debate sobre os conflitos e disputas por um projeto de desenvolvimento desigual de dominação ou para uma sociedade que respeite cidadãos e cidadãs da floresta, do campo e das águas. As possiblidades de resistências da população ao enfrentamento dos conflitos e violações de direito no território são reais e em construção. Percebe-se que a produção da contra-informação, ainda que incipiente, é necessária e contribui para debates e acesso a outras informações da população em situação de risco e vulnerabilidade social, como a população ribeirinha.

Mediante as reflexões aqui apresentadas, há um grande desafio de articular participação popular e políticas públicas no território de Anajás, fato desencadeado pelo processo sociohistórico em que o município está inserido. Tal processo marcado pela exploração e expropriação do território que trouxe como consequência uma profunda carência de políticas públicas, da preservação cultural, dos conhecimentos acerca da própria história. A invisibilidade da população ribeirinha está ligada às estratégias capitalista sob perspectivas neoliberais e neodesenvolvimentista, que veem essa população como empecilhos de desenvolvimento econômico.

Por isso, a ausência das políticas públicas torna-se cada vez mais comum, pois com a sua efetivação, é possível possibilitar o reconhecimento e discussão das demandas da população ribeirinha. As discussões também podem ser no sentido de criar estratégias de atividades ecologicamente concebidas para o território, propondo alternativas de atividades condizentes com a cultura ribeirinha. E é nítida a necessidade da criação de espaços que possam fazer com que as populações tradicionais exerçam a sua autonomia, como sujeitos políticos, para construir alternativas para a sua reprodução social e coletiva como direito socioterritorial na Amazônia.

\section{REFERÊNCIAS}

ABEP - Associação Brasileira de Empresas de Pesquisa. Nascimentos e dinâmica populacional em Anajás, arquipélago do Marajó de 1890 a 1940. São Paulo. 2018. Disponível em: http://www.abep.org.br/xxencontro/files/paper/238-373.pdf. Acesso em 06 de março de 2020.

ALEPA - ASSEMBLÉIA LEGISLATIVA DO ESTADO DO PARÁ. Comissão Parlamentar de Inquérito: instituída para apurar a prática de violência e abuso sexual contra crianças 
e adolescentes no estado do Pará e especialmente na região do Marajó nos últimos cinco anos. Fevereiro de 2010. Disponível em: https://www.alepa.pa.gov.br/relatorios. Acesso em: 13 de julho de 2020.

AÇÃO CIVIL PÚBLICA - MINISTÉRIO PÚBLICO FEDERAL - Ementa: Leilão do Marajó. Comunidades Tradicionais. Regularização Fundiária. Terras da União. SPU. RECOMENDAÇÃO no /2016. Belém/PA, 26 de agosto 2016.

ATLAS BRASIL. Disponível em: http://atlasbrasil.org.br/2013/pt/ranking/. Acesso em 05 de março de 2020.

BRASIL. Constituição (1988). Constituição da República Federativa do Brasil [recurso eletrônico]. - Brasília: Supremo Tribunal Federal, Secretaria de Documentação. Atualizada até a EC n. 105/2019. Disponível em: https://www.stf.jus.br/arquivo/cms/legislacaoConstituicao/anexo/CF.pdf. Acesso em 25 de março de 2020.

BRASIL. Governo Federal. Grupo Executivo Interministerial. Plano de Desenvolvimento Territorial Sustentável para o Arquipélago do Marajó: resumo executivo da versão preliminar para discussão nas consultas públicas / Governo Federal, Grupo Executivo Interministerial. - Brasília: Editora do Ministério da Saúde, 2007.

BRASIL. Regulamentação da Profissão de Assistente Social, Lei No 8.662, de 07 de junho de 1993.

CANELLAS, Marcelo. Anajás (PA) tem quase metade da população com casos de malária. Jornal eletrônico G1 Pará. 2010. Disponível em: http://g1.globo.com/bom-dia-brasil/noticia/2010/11/anajas-pa-tem-quase-metade-da-populacao-com-casos-de-malaria.html. Acesso em 23 de março de 2020.

CFESS. Código de Ética Profissional dos Assistentes Sociais e outras providências, Resolução CFESS N. ${ }^{\circ}$ 273/93, de 13 de março de 1993.

COSTA, Najara Mayla do Socorro Veiga. Amazônia do Contexto da Acumulação Capitalista: a particularidade de pequenas cidades amazônicas. 2015.

DALFIOR, Eduardo Tonole; LIMA, Rita de Cássia Duarte; ANDRADE, Maria Angélica Carvalho. Implementação de políticas públicas: metodologia de análise sob o enfoque da política institucional. Saúde debate [online]. 2015. vol. 39. pp.283-297.

KAYSER, Erick. Neoliberalismo e Necropolítica. IHU-Unisinos. 12 Dezembro de 2019. Disponível em: http://www.ihu.unisinos.br/78-noticias/595098-neoliberalismo-e-necropolitica. Acesso em: 29 de março de 2020.

IBGE - Instituto Brasileiro de Geografia e Estatística. 2017. Biblioteca IBGE - Anajás - PA: Disponível._http://biblioteca.ibge.gov.br/visualizacao/dtbs/para/anajas. Acesso em 07 de março de 2020.

IBGE - Instituto Brasileiro de Geografia e Estatística. Censo demográfico 2010 e Mapa de Pobreza e Desigualdade dos Municípios Brasileiros. Disponível em: www.ibge.gov.br. Acesso em: 18 abr. 2018.

HARVEY, David. O Novo imperialismo. $7^{\mathrm{a}}$ Ed. São Paulo: Edições Loyola, 2003.

MATOS, Edmundo da S. Território, Ambiente e Gestão. In: HISSA, Cássio E (org). Saberes ambientais - desafios para o conhecimento disciplinar. Ed. UFMG, 2008.

Mathis et al.. Desenvolvimento, neodesenvolvimento e impactos sobre o trabalho na Amazônia brasileira. NOVOS CADERNOS NAEA, v. 19 n. 1, p. 237-252, 2016.

POLÍTICA NACIONAL DE ASSISTÊNCIA SOCIAL - PNAS, aprovada pela Resolução no145, de 15 de outubro de 2004, do CNAS. 
PREFEITURA MUNICIPAL DE ANAJÁS. Disponível em: https://anajas.pa.gov.br/o-municipio/historia/. Acesso em 04 de março de 2020.

REDE ECLESIAL PAN-AMAZÔNICA. REPAM-Brasil. Sínodo para a Amazônia. 08 de janeiro de 2020. Disponível em: https://repam.org.br/?page_id=962. Acesso em 20 de julho de 2020.

ROSSI, Amanda. Por que os casos de malária cresceram 50\% no Brasil após 6 anos de queda. BBC Brasil. São Paulo. 4 maio 2018. Disponível em: https://www.bbc.com/portuguese/brasil-43998843. Acesso em 21 de julho de 2020.

SÁ, Maria Elvira R. ; FIALHO NASCIMENTO, Nádia Socorro. VII Colóquio Marx e ENgels. Amazônia, multinacionais e "questão Social": reflexões à luz da teoria crítica. 2012.

SANTOS, Rodrigo Salles Pereira dos. MILANEZ, Bruno. Neoextrativismo no Brasil? Atualizando a análise da proposta do novo marco legal da mineração. v. 10, n. 19, 2013.

SAQUET, Marcos Aurélio; SPOSITO, Eliseu Savério. (Org.). Território e Territorialidades: teorias, processos e conflitos. $1^{\mathrm{a}}$ ed. São Paulo; Expressão Popular: UNESP. 2008.

SARRAF-PACHECO, Agenor. Cartografia \& Fotoetnografia das Águas: modos de vida e de luta na Amazônia marajoara. Iluminuras, Porto Alegre, v. 19, n. 46, p. 63-98, jan/jul, 2018.

Serviço Brasileiro de Apoio às Micro e Pequenas Empresas/MG (SEBRAE/MG). Políticas públicas: conceitos e práticas. Supervisão de Brenner Lopes e Jefferson Ney Amaral; Coordenação de Ricardo Wahrendorff Caldas. Belo Horizonte: SEBRAE/MG, 2008.

SILVA, Maria das Graças e. Sustentabilidade socioambiental e a retórica neodesenvolvimentista: apontamentos sobre meio ambiente no Brasil. Serviço Social \& Sociedade., São Paulo, n. 123, p. 428-446, Set. 2015.

SPOSATI, Aldaíza. Território e gestão de políticas sociais. Serviço Social em Revista, v. 16, p. 05-18, 2013.

UNIVERSIDADE FEDERAL DO PARÁ. Diretrizes Gerais do Estágio Curricular da Faculdade de Serviço Social (FACSS), do Campus Universitário do Marajó - Breves. Breves: UFPA, 2011. 